\title{
Catheter Reprocessing for Coronary Angiography: It is Not Safe
}

\author{
Dinaldo C. Oliveira ${ }^{\mathrm{a}, \mathrm{b}}$, Flavia Bonfimª, Maria Vinhas ${ }^{\mathrm{a}}$, Ivan Silva ${ }^{\mathrm{a}}$, \\ Magno Teixeira ${ }^{\mathrm{a}}$, Andre Galembeck ${ }^{\mathrm{a}}$
}

\begin{abstract}
Background: Coronary angiography and percutaneous coronary intervention are frequently and increasingly performed worldwide. Although catheters for coronary angiography are considered as single-use devices, some people still question this decision. This study evaluated the structural characteristics and thermal stability of new and reprocessed catheters.
\end{abstract}

Methods: Five catheters (Judkins left) of the same brand and manufacturer were selected for each analysis. We evaluated: new catheters, catheters reprocessed once (first), twice (second), thrice (third), and seven times (seventh). The optical analyses of the proximal, middle and distal parts of the catheters were performed by magnifying glass. Besides, thermogravimetric analyses were done.

Results: After reprocessing, the crushing, color changes, folds, dents, deformations, and lumen narrowing were observed; the stainless-steel framework, the external tortuosity, the interlaced mesh of stainlesssteel wires and loss of polymeric material were visualized. Thermogravimetric analysis showed lost of mass of the catheters.

Conclusions: This study demonstrated that the structural integrity and mass of catheters are lost with reprocessing. These findings may be caused by several steps of reprocessing; however, regardless of which step or steps were responsible, the presence of structural integrity loss leads to the recommendation of not reusing this type of device.

Keywords: Coronary angiography; Catheters; Catheterization laboratory; Reprocessing; Magnifying glass

\section{Introduction}

Diagnostic and therapeutic procedures in the catheterization

Manuscript submitted July 15, 2020, accepted July 28, 2020

Published online August 7, 2020

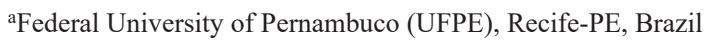
${ }^{b}$ Corresponding Author: Dinaldo C. Oliveira, Federal University of Pernambuco (UFPE), Rua Prof. Moraes Rego 1235, CEP 50670-901, Recife-PE, Brazil. Email: dinaldo@cardiol.br

doi: https://doi.org/10.14740/cr1134 laboratory are frequently and increasingly performed worldwide. Coronary artery angiography and percutaneous coronary intervention have been two of the most frequently performed procedures [1].

Coronary artery disease (CAD) is responsible for millions of deaths or occurrence of disabilities. Many patients with $\mathrm{CAD}$ are treated with surgical or percutaneous revascularization, a procedure with an important prognostic impact because it can prolong and improve the quality of life $[2,3]$.

Myocardial revascularization cannot be performed without previous coronary angiography. Therefore, a catheter is fundamentally used in the management of patients with CAD [4].

Although catheters for coronary angiography are considered as single-use devices, reprocessing and reusing them have been clinically practiced for a long time [5]. This process has been banned in many countries; however, some people still question this decision.

In this study, we evaluated the structural characteristics and thermal stability of new and reprocessed catheters to identify possible changes after reprocessing.

\section{Materials and Methods}

Five catheters (Judkins left) of the same brand and manufacturer were selected for each analysis. We evaluated: new catheters, catheters reprocessed once (first), twice (second), thrice (third), and seven times (seventh). The optical analyses of the proximal, middle and distal parts of the catheters were performed by magnifying glass. Besides, thermogravimetric analysis (TGA) was done. This is an experimental study which was approved by the institutional review board; and no human or animal materials were evaluated.

\section{Reprocessing}

All catheters were sterilized in the factory using ethylene oxide and placed inside a clear plastic Tyvek ${ }^{\circledR}$ (DuPont trademark) packaging. The reprocessing phases were performed as follows. In the first phase, the catheter was cleaned using a heparinized solution to remove blood residues. In the second phase, the lumen was irrigated; and in the third phase, the external part of the catheter was cleaned manually. In the fourth phase, the catheters were immersed in an antiseptic solution. 
In the fifth phase, they were removed from the antiseptic solution and dried first at the room temperature and then in compressed air at variable pressure, as required. Catheters were subsequently sterilized using hydrogen peroxide plasma gas.

\section{Magnifying glass analysis}

Analyses were performed in the Zeiss ${ }^{\circledR}$ device known as magnifying glass, an objective plane model S-1.0X FWD-81MM, in parts of catheters described and listed below: proximal, middle, and distal to verify portions with irreversible damage during reprocessing, determining the visualization of all catheters in their full extent (Fig. 1).

Five parts of the catheter samples (one of the distal, three of the middle, and one of the proximal portions) were used during the new, first, second, and third reprocessing. The catheters were placed at the middle of a laboratory bench, divided into two parts, concave and convex, to facilitate internal and external visualization of the catheters.

\section{TGA}

In the TGA, a NETZCH ${ }^{\circledR}$ brand equipment, model STA 449 F3 Jupiter, with sensors for the simultaneous TGA and differential scanning calorimetry (DSC) was used. It was properly calibrated to reliably generate mass and energy data, under the following conditions: nitrogen atmosphere, at $50^{\circ} \mathrm{C} / \mathrm{min}$ rate, submitted to isothermal heating in the $40-700{ }^{\circ} \mathrm{C}$ range, with a $10{ }^{\circ} \mathrm{C} / \mathrm{min}$ heating rate.

\section{Results}

\section{Magnifying glass analysis}

\section{New catheter}

Images of the new catheter do not show any apparent flaws, because it has not been used and not yet passed through any

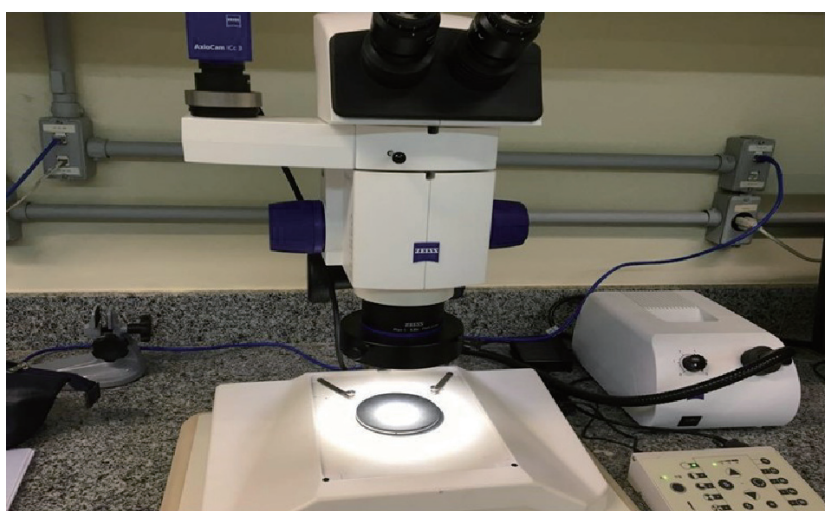

Figure 1. Magnifying glass ZEISS ${ }^{\circledR}$ Objective Plane S-1.0X FWD$81 \mathrm{MM}$.

stage of reprocessing. These images show that the parts collected from the catheters did not present any problems that limit the use of the catheter.

\section{First reprocessing}

After the first reprocessing, crushing and color changes were observed at the distal portion, whereas folds, dents, and deformations leading to light narrowing were observed at the middle and proximal portions (Fig. 2).

\section{Second reprocessing}

After the second reprocessing, opacity of the distal part of the catheter and appearance of two colors were observed, in addition to a fold discoloration and lumen narrowing in the proximal part. The stainless-steel framework can also be visualized (Fig. 3).

\section{Third reprocessing}

After the third reprocessing, sharp folds, color changes, ex-

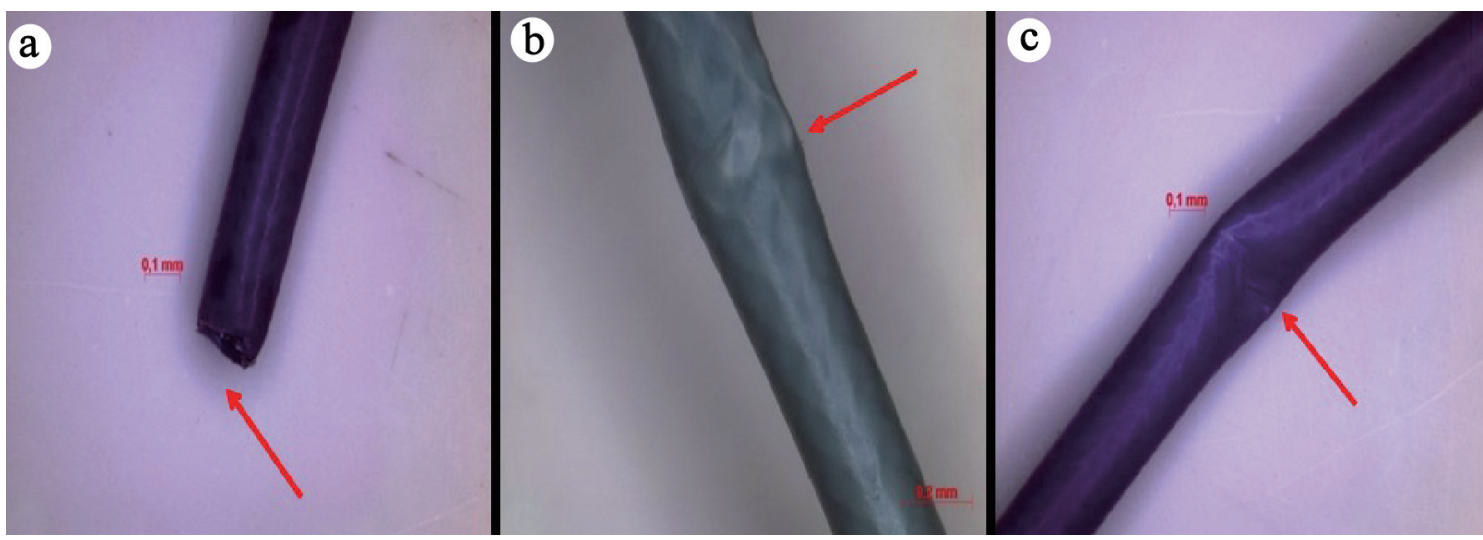

Figure 2. Dents and deformations after first reprocessing: (a) Distal; (b) Middle; (c) Proximal. 


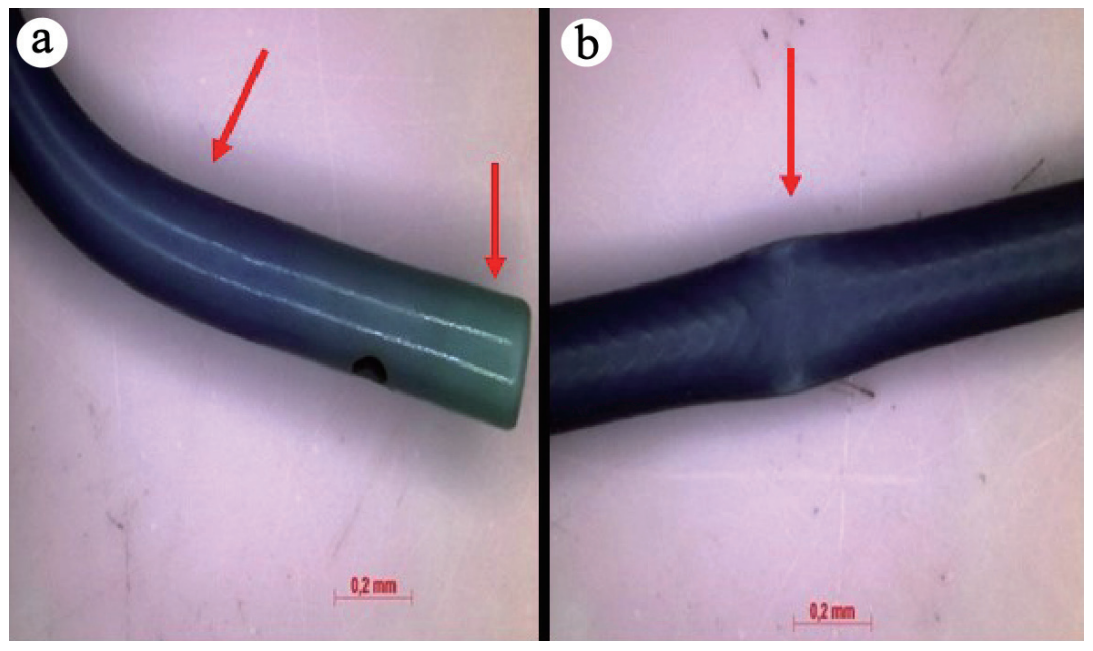

Figure 3. Appearance of two colors and deformations after second reprocessing: (a) Distal; (b) Middle.

ternal tortuosity, visualization of the interlaced mesh of stainless-steel wires, decreased lumen size, loss of polymeric material in the proximal, middle, and distal parts were observed (Fig. 4).

\section{Seventh reprocessing}

There were no additional damages compared with third reprocessing.

\section{TGA}

During the TGA, catheter reprocessing also generates changes in thermal properties of the material, as can be observed in the thermogram shown in Figure 5.

Table 1 shows the results of the TGA and DTG. With the presence of three stages of mass loss, the initial and final temperatures of each stage can be noted. There was lost of mass according to reprocessing, and it was clear that the increasing number of reprocessing was numerically associated with reduction of mass (residual mass: first reprocessing $=60 \%$, sec- ond $=58 \%$, third $=59 \%$ and seventh $=51 \%$ ).

\section{Discussion}

This study demonstrated that the structural integrity and mass of catheters are lost with reprocessing. These findings may be caused by several steps of reprocessing; however, regardless of which step or steps were responsible, the presence of structural integrity loss leads to the recommendation of not reusing this type of device.

The magnifying glass is an optical instrument equipped with a lens capable of creating magnified virtual images, with a magnification capacity of 8.0 times. It is used to observe small objects and some details or surfaces more easily. It is also known as a simple microscope, consisting of a single convergent lens $[6,7]$.

To understand how the magnifying glass works, how the magnifying glass conjugates images and how these images (virtual objects for our eye) end up being projected on our retina should be analyzed. The human eye only focuses on an image of an object on its retina if the distance between the object and the eye is greater than that of a specific point (near

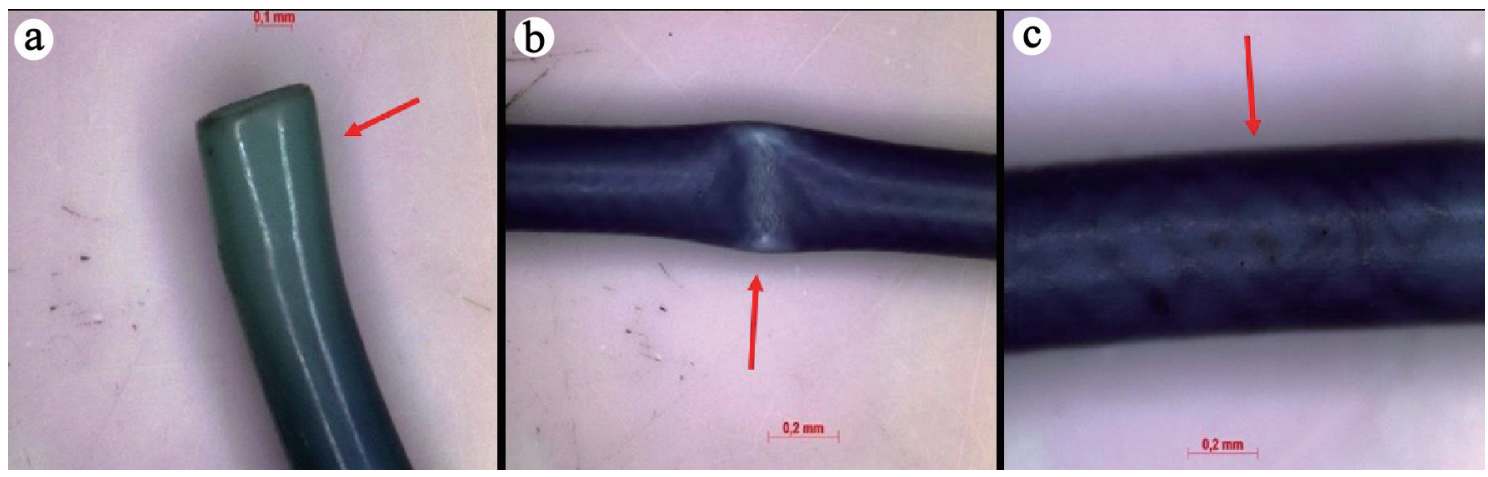

Figure 4. Sharp folds, color changes and visualization of the interlaced mesh of stainless-steel wires after third reprocessing: (a) Distal; (b) Middle; (c) Proximal. 

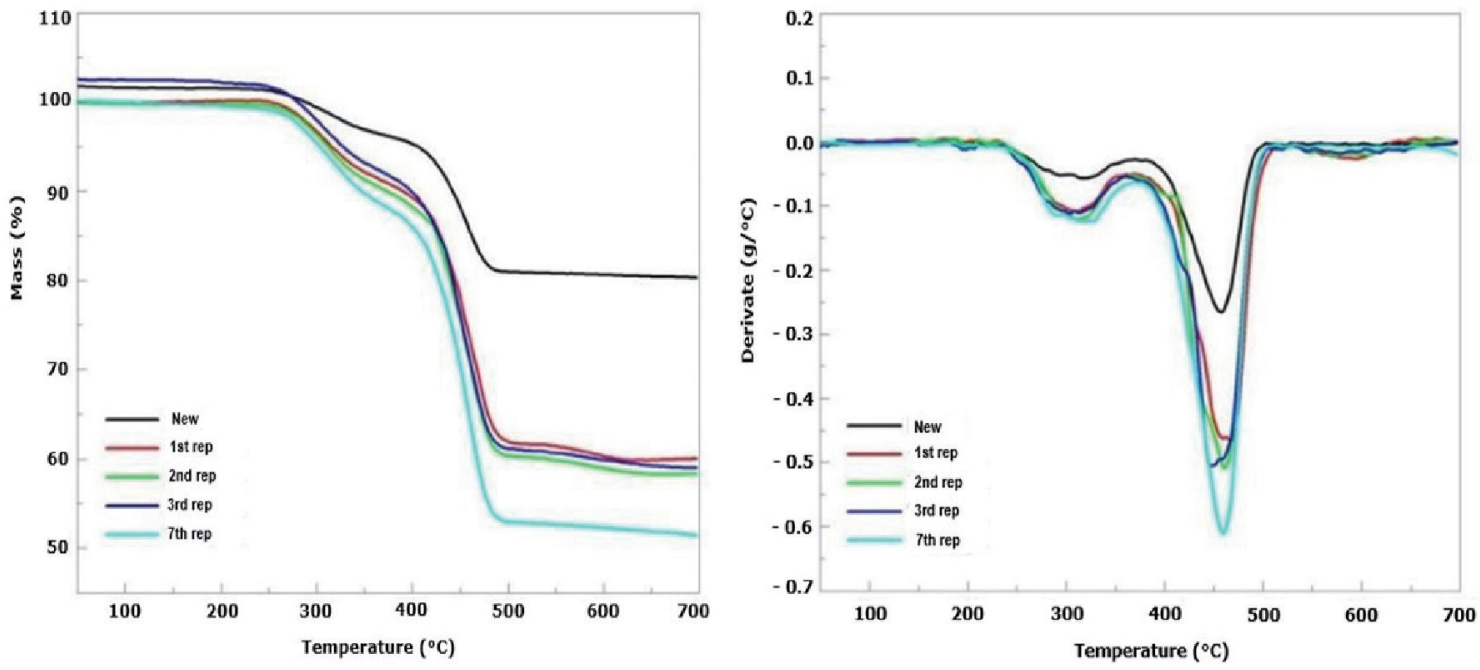

Figure 5. Changes on thermal characteristics. (a) Thermogravimetric curves; (b) Derivative of the thermogravimetric curves.

point). It can easily be observed that when the object is closer to the eye, the distance from the near point the image becomes blurred $[6,7]$.

The position of the near point may vary from person to person. This distance is commonly longer in older people. Imagine an object placed over the near point of a human eye, the size of the image produced on the retina varies with the angle $\alpha$ ( $\alpha=$ supplementary angle) that the object occupies in the field of view; therefore, when the object is approaching the eye, this angle is increased, which consequently increases the ability to observe details of the subject. However, as the subject is at a shorter distance than the near point, it is seen out of focus, losing its sharpness $[6,7]$.

For the blurred image to be sharp again, a convergent lens should be placed between the eye and the subject (the subject must be closer to the eye than the focal point of the lens). What the eye starts to see is a virtual image of the object. This image is more distant from the eye than the near point and is now clearly visible. Despite this magnification, the magnifying glass is not suitable for the observation of very small objects, such as cells, bacteria, and small insects, because these require a very large magnification. The solution is to associate two or more convergent lenses, as in the compound microscope $[6,7]$.

When single-use devices are repeatedly used, it is expected to gradually wear out of the original functionality. Physical and mechanical properties tend to deteriorate with continuous use. Cleaning processes using detergents or other chemicals, not foreseen in the manufacture of the products, may alter the composition of the polymers. Catheters made of polyvinyl chloride (PVC), particularly when deteriorated, become less flexible and more fragile since contact with the organic solvent promotes extraction of the additive from the formulation of these artifacts. However, polyester-based catheters can be hydrolyzed, compromising the chemical structure of the material's main chain [8-10].

In one of the reprocessing steps, catheter sterilization is usually performed through the hydrogen peroxide substrate with plasma generation. This sterilizing agent has great potential for the interaction with the polymeric chain of the material, the formation of oxygenated groups that can initiate the cleavage of chains, and the formation of cross-links, contributing to the deterioration of the material and alteration of mechanical properties, characterized by rigidity, during different cycles of reprocessing. Therefore, repetition of reprocessing can compromise the functionality of the catheter $[10,11]$.

Several clinical studies of reuse of SUDs including electrophysiology catheters, angioplasty balloons, single-use endoscopic instruments, etc., have established their relative safety without increasing patient risk of infections or pyrogenic reactions [5]. However, other studies showed that the appear-

Table 1. Stages of Mass Lost According to Thermogravimetric Analysis

\begin{tabular}{|c|c|c|c|c|c|c|c|}
\hline \multirow{2}{*}{ Samples } & \multicolumn{2}{|c|}{ First $\left({ }^{\circ} \mathrm{C}\right)$} & \multicolumn{2}{|c|}{ Second $\left({ }^{\circ} \mathrm{C}\right)$} & \multicolumn{2}{|c|}{ Third $\left({ }^{\circ} \mathrm{C}\right)$} & \multirow{2}{*}{ Residual mass (\%) } \\
\hline & $\mathbf{T}(\mathrm{I})$ & $\mathbf{T}(\mathbf{F})$ & $\mathbf{T}(\mathrm{I})$ & $\mathbf{T}(\mathbf{F})$ & $\mathbf{T}(\mathrm{I})$ & $\mathbf{T}(\mathbf{F})$ & \\
\hline New & 232 & 365 & 384 & 504 & - & - & 80 \\
\hline 2en reprocessing & 233 & 365 & 367 & 513 & 519 & 679 & 58 \\
\hline 3 rd reprocessing & 232 & 357 & 368 & 505 & 519 & 680 & 59 \\
\hline
\end{tabular}

T: temperature; I: initial; F: final. 
ance of cracks, crevices, and roughness in the material surfaces are indispensable for predicting the occurrence of infectious processes such as pyrogenic or endotoxic reactions that can induce the manifestations of unexplained fevers, tremors, and physiological changes. These intercurrences can be serious and endanger the patients' lives [10, 12-17].

In addition, according to some authors reprocessing results in the accumulation of biofilms and endotoxins within microcracks, which may lead to infections and the development of thrombi in patients [17]. These complications include embolic cerebrovascular accidents, neurological deficits, and blindness in patients after fragments of reprocessed catheters lodged in the heart, in the left carotid artery of the intracranial portion, and in the central artery of the retina [10, 17-21]. Myrna et al [22] evaluated the characteristics of the catheter by eletron microscopy after reprocessing and showed that there were a lot of damages. Besides, physical properties (for example flexibility and resistance to torque) must be preserved. Micro-fissures, micro-scratches, hollows, micro-protrusions, loss of the deflection were described after reprocessing [23]. Therefore, physical integrity may be lost due to reprocessing and it may compromise manoeuvrability.

Therefore, risks of relevant clinical outcomes related to catheters and characteristics of structural integrity loss were found in this study. Due to the limited health budgets in some countries, risks caused by catheter reprocessing remain, which do not justify such practice.

According to the TGA, masses of reprocessed catheters were numerically lower than those of the new ones. Heilman et al [24] argued that the loss of mass in the first two stages is fundamentally related to the degradation of organic materials, i.e., the polymeric material constituting the catheter. The third stage is related to the degradation of inorganic compounds or carbonaceous materials. Therefore, the finding of this study corroborates the structural loss of reprocessed catheters.

\section{Conclusions}

In the modern world, healthcare issues have been increasing, contributing to the emergence of specialties in which the advances have been remarkable, allowing the extension of human life and better quality of life. However, significant financial costs were associated with some of these scenarios [25].

Modern cardiology has incorporated several multidisciplinary aspects to healthcare, and this has been determinant for its advance and positive impact on modern society. However, there is a financial bill to be paid. Unfortunately, several countries do not have healthcare budgets that meet all these needs, and unfortunately, choices have been made. This study reinforces the recommendation that the choice of catheter reprocessing for coronary angiography should not be made because of the real risk of harming the patients.

\section{Acknowledgments}

We would thank all people from catheterization laboratory at the Hospital Ilha do Leite, HAPVIDA.

\section{Financial Disclosure}

None to declare.

\section{Conflict of Interest}

None to declare.

\section{Informed Consent}

Not applicable.

\section{Author Contributions}

Dinaldo Oliveira: acquisition and analysis of data, draft work, and final approval. Flavia Bonfim: acquisition and analysis of data, draft work, and final approval. Maria Vinhas, Ivan Silva, Magno Teixeira, and Andre Galembeck: final approval.

\section{Data Availability}

The data supporting the findings of this study are available from the corresponding author upon reasonable request.

\section{References}

1. Virani SS, Alonso A, Benjamin EJ, Bittencourt MS, Callaway CW, Carson AP, Chamberlain AM, et al. Heart disease and stroke statistics-2020 update: a report from the American Heart Association. Circulation. 2020;141(9):e139-e596.

2. Ibanez B, James S, Agewall S, Antunes MJ, BucciarelliDucci C, Bueno H, Caforio ALP, et al. 2017 ESC Guidelines for the management of acute myocardial infarction in patients presenting with ST-segment elevation: The Task Force for the management of acute myocardial infarction in patients presenting with ST-segment elevation of the European Society of Cardiology (ESC). Eur Heart J. 2018;39(2):119-177.

3. Knuuti J, Wijns W, Saraste A, Capodanno D, Barbato E, Funck-Brentano C, Prescott E, et al. 2019 ESC Guidelines for the diagnosis and management of chronic coronary syndromes. Eur Heart J. 2020;41(3):407-477.

4. Neumann FJ, Sousa-Uva M, Ahlsson A, Alfonso F, Banning AP, Benedetto U, Byrne RA, et al. 2018 ESC/ EACTS Guidelines on myocardial revascularization. Eur Heart J. 2019;40(2):87-165.

5. Kapoor A, Vora A, Nataraj G, Mishira S, Kerka P, Manjunath $\mathrm{CN}$. Guidance on reuse of cardiovascular cateter and devices in India: A consensus document. India Heart J. 
2017;69(3):357-363.

6. Callister WD. Materials science and engineering. Jonh Whiley \& Sons Ltd, 7a. Ed. New York. 2007.

7. Silveira FL, Axt R, Pires MA. What do we view looking to ourselves in a concave mirror? Revista Brasileira de Ensino de Fisica. 2004;26:19-25.

8. Instituto Brasileiro de PVC. Artigos tecnicos da area medica. Obtido no site: http://www.pvc.org/br/conhecimentoi/artigos-tecnicos.

9. Graziano KU, Castro MES, Moura MLPA. A importancia do procedimento de limpeza nos processos de desinfeccao e esterilizacao de artigos. Rev SOBECC. 2002;7:9-23.

10. Lucas TC. Validacao do reprocessamento de cateteres cardiacos angiograficos: uma avaliacao da funcionalidade e intergidade. https://repositorio.ufmg.br/handle/1843/ GCPA-7PMNTP.

11. Carey J, Emery D, McCracken P. Buckling test as a new approach to testing flexural rigidities of angiographic catheters. J Biomed Mater Res B Appl Biomater. 2006;76(1):211-218.

12. Dunn D. Reprocessing single-use devices - the equipment connection. AORN J. 2002;75(6):1143-1158; quiz 1159, 1161-1144.

13. Shafferman ASL, Lacerda RA. Reuso de produtos de uso unico na area da saude. Simposio Internacional - Escola de Enfermagem - USP, Maio. 2006. https://docplayer. com.br/.

14. Denser CPAC, Lacerda RA. Reprocessamento e reutilizacao de material odonto-medico-hospitalar de uso unico: busca de evidencias pela revisao sistematica de literatura cientifica. Acta paul enferm. 2006;19:316-322.

15. Baffi SHEO, Lacerda RB. A busca de qualidade no reprocessamento e na reutilizacao de cateteres de hemodinamica. Rev SOBECC. 2001;6:23-30.
16. Silva RC, Silva RM, Aquino K AS. A Interacao da Radiacao Gama com a Materia no Processo de Esterilizacao Rev. Virtual Quim. 2014;6:1624-1641.

17. Lucas TC, Barbosa MP, Oliveira AC. Reprocessing validation of cardiac catheters: na evaluation of functionality and intergrity. Rev Esc Enferm USP. 2010;44:945-952.

18. Tessarolo F, Ferrari P, Silvia B, Motta A, Migliaresi C, Zennaro L, et al. Evaluation and qualification of reprocessing modification in single-use devices in interventional cardiology. Appl Surf Sci. 2004;238:341-346.

19. Harikrishnan S, Rajeev E, Nair K, Tharakan J. Retrieval of friable catheter fragments. Int J Cardiol. 2006;106(2):282-284.

20. Oliveira DC, Wanick S, Gomes V, Victor E. Riscos da Reutilizacao de Cateteres no Laboratorio de Cardiologia Invasiva e Hemodinamica. Revista Norte Nordeste de Cardiologia. 2014;4:1-4.

21. Smith JJ, Berlin L. Reusing catheters and other medical devices. AJR Am J Roentgenol. 2001;177(4):773-776.

22. Myrna F, Oliveira DC, Vinhas G, Silva I, Teixeira M, Galembeck A. Reprocessing of catheters used for coronary angiography and changes in the polymeric structures. Cardiol Res. 2018;9(5):300-306.

23. Gelamo RV, Sene EC, Paiva L, Oliveira Cda C, Maltos AL, Schreiner WH, Moraes MB, et al. Effects of reprocessing on chemical and morphological properties of guide wires used in angioplasty. Rev Bras Cir Cardiovasc. 2013;28(3):331-337.

24. Heilman S. Efeito da radiacao ionizante nos revestimentos de cateteres de poliuretano com nanoparticulas de prata. https://teses.usp.br.

25. Use of Catheter Reprocessing to Reduce Cath and EP Lab Costs. https://www.dicardiology.com/article/use-catheter-reprocessing-reduce-cath-and-ep-lab-costs. 